\title{
Constraining the comprehension of pronominal expressions in Chinese
}

\author{
Chin Lung Yang ${ }^{\mathrm{a}}$, Peter C. Gordon ${ }^{\mathrm{a}, *}$, \\ Randall Hendrick ${ }^{\mathrm{a}}$, Chih Wei Hue ${ }^{\mathrm{b}}$ \\ ${ }^{a}$ University of North Carolina at Chapel Hill, Chapel Hill, NC, USA \\ ${ }^{\mathrm{b}}$ National Taiwan University, Taipei, Taiwan
}

Received 6 December 2000; received in revised form 30 May 2002; accepted 14 September 2002

\begin{abstract}
This paper reports a series of self-paced reading time experiments designed to probe how the reference of pronominal expressions is resolved on-line in (Mandarin) Chinese. It is assumed that pronoun resolution is achieved by narrowing the candidate set of potential antecedents for a pronoun. The experimental evidence reported here indicates that two factors - syntactic prominence and the matching of lexical features (e.g. gender) - play a significant role in filtering this candidate set. It is shown that syntactic prominence and feature matching work in conjunction with each other rather than in a competitive, winner-take-all manner. Furthermore, the evidence suggests that syntactic prominence is sensitive to structural relations rather than exclusively to grammatical functions (such as subject and direct object) or semantic roles (such as agent and patient) as has been assumed in the psycholinguistic literature. (C) 2002 Elsevier Science B.V. All rights reserved.
\end{abstract}

Keywords: Constraining; Comprehension; Pronominal expressions; Chinese; Syntax

\section{Introduction}

Isolating the cognitive mechanisms that interpret pronominal expressions is a central issue in the cognitive sciences. Pronominals do not have an invariant referent but instead refer to different entities depending on the social and linguistic context that makes up the universe of discourse in which they appear. Thus, they offer a special vehicle for probing cognition as it is situated in context. In most cases the pronominal inherits its referent from another expression, its "antecedent". Together the antecedent and the pronominal "corefer" to the same entity in the universe of discourse. Most attempts to make the problem

\footnotetext{
* Corresponding author. Department of Psychology, The University of North Carolina at Chapel Hill, CB\# 3270, Davie Hall, Chapel Hill, NC 27599-3270, USA. Tel.: +1-919-962-2440; fax: +1-919-962-2537.

E-mail address: pcg@email.unc.edu (P.C. Gordon).
} 
tractable adopt the strategy of hypothesizing constraints (or filters) that contribute to the interpretation of the pronominal by limiting the set of potential antecedents. While different disciplines have addressed pronominals and the factors constraining their interpretation, they have chosen to focus on distinct facets of the phenomena. In the process, they have engendered rather disparate theories that, we believe, need to be drawn into closer coordination.

\subsection{Different theories, differing goals}

Linguistics has focused on the pattern of interpretation within a single utterance. The dominant theory in this domain is a structural (or "categorial") one (Chomsky, 1986). It identifies a privileged structural relation (the relation of c-command; Reinhart, 1983) that serves as a filter to exclude some nominal expressions in the utterance from being a potential antecedent for the pronominal. There is no attempt to provide a mechanism that determines the antecedent for the pronominal; it is assumed that this lies outside the domain of sentence grammar (Lasnik, 1976). Competing theories adopt the same general strategy of specifying what nominal expressions are excluded as potential antecedents. They differ principally in whether those excluded nominal expressions are identified by non-structural criteria such as grammatical function (e.g. subject, direct object, etc.) or semantic role (e.g. argument of a predicate, agent, etc.). Bresnan (1999) is an example of work appealing to grammatical functions; Partee and Bach (1981), Keenan (1974), and Williams (1994) all appeal to semantic roles. The differences between these competing approaches are most visible in their treatment of sentences that lack phonologically realized subjects. The sentences in (1)(3) have similar meanings but very different superficial forms.

\section{(1) I speak Chinese}

(2) Hablo

speak- $1^{\text {st }}$ person-singular chino

\section{Chinese}

\section{I speak Chinese}

\section{(3) $\varnothing$ 說 中文。 \\ $\varnothing$ speak Chinese. \\ "(I) speak Chinese."}

A structural account recognizes an implicit but phonologically unexpressed pronoun in (2) and (3), parallel to the English "I". ${ }^{1}$ A semantic account avoids making the structure of these

\footnotetext{
${ }^{1}$ This approach can be seen in Jaegli and Safir (1989).
} 
sentences parallel but expresses their similarity in terms of a semantic property (e.g. agent) that is shared by all three examples. An account based on grammatical functions only posits a pronoun in (1). In (2) the grammatical function subject is paired with the verbal inflection expressing the subject's person and number features. In the Chinese example (3), where there is neither an expressed pronoun nor any verbal inflection, the grammatical function subject is not paired with any overt element in the sentence structure. It remains implicit, present only in the functional requirements of the verbal predicate. ${ }^{2}$

Psychology and computer science have pursued a different goal. Their research objective has been to understand how an antecedent for a pronominal is selected from a discourse model built up from a series of utterances (cf. Johnson-Laird \& Garnham, 1980; McKoon \& Ratcliff, 1992). This ambitious goal is an issue that linguistics is largely silent on. These disciplines attempt to construct algorithms that determine the preferred antecedent of a pronominal. In this search some psychological studies (e.g. Gernsbacher, 1989) have drawn attention to the role of world knowledge. Computer scientists have devoted more attention to how such appeals to world knowledge can be made explicit, typically by way of conventionalized constraints on interpretation (Hobbs, 1979; Partridge, 1991; Schank, 1973). Interesting work has shown in some detail how distinct semantic classes of verbs help to narrow the selection of an antecedent for a pronominal (Ehrlich, 1980; Garnham, Traxler, Oakhill, \& Gernsbacher, 1996; McDonald \& MacWhinney, 1995). There is also evidence that the antecedent of a pronominal is selected from the set of nominals matching its lexical, morphosyntactic features such as number and gender (Garnham \& Oakhill, 1985; MacDonald \& MacWhinney, 1995; Matthews \& Chodorow, 1988; Shillcock, 1982). For utterances making use of verbs from the same semantic class, where morphosyntactic cues do not identify a unique antecedent, there appears to be some filtering effect of syntactic organization. The literature in this area has not made many assumptions about what aspect of syntactic organization is relevant. Theoretical linguistics distinguishes structural (or categorical) information from grammatical functions (such as subject or direct object). For the most part researchers in psycholinguistics have employed the terminology of grammatical function uncritically. One strand of thought uses grammatical functions to require a pronominal to find an antecedent with the same or "parallel" grammatical function (Grober, Beardsley, \& Caramazza, 1978; Sheldon, 1974) or with a privileged grammatical function, typically "subject" (Crawley, Stevenson, \& Kleinman, 1990; Fredericksen, 1981; Smyth, 1994). A second strand of thought identifies a metric of discourse prominence that ranks potential antecedents. The influential work of Grosz, Joshi, and Weinstein (1995) makes the assumption that this ranking is determined by the grammatical function of NPs, although other syntactic factors have also been advocated (Strube \& Hahn, 1999). The work reported in Gordon and Scearce (1995), Gordon and Chan (1995), and Gordon, Grosz, and Gilliom (1993) provides some experimental corroboration for the utility of such definitions of discourse prominence. It remains to be determined experimentally whether the syntactic effect is best modeled as a consequence of grammatical functions or of structural or semantic factors. A final approach to such issues would frame the problem in terms of the frequency of words and the co-occurrence of words, arguing that ease of

${ }^{2}$ See the discussion in Bresnan (2001, p. 204). 
processing should be understood with respect to frequency of tokens rather than with respect to the understanding of language in terms of the manipulation of symbols and syntactic structures (e.g. MacDonald, Pearlmutter, \& Seidenberg, 1994 for the case of syntactic ambiguity). This approach is limited both by the absence of the relevant language statistics in many interesting cases, and by the difficulties in drawing causal inferences from correlations between frequency and processing ease.

It should be clear from this foreshortened overview that the general directions of research in linguistics and in psychology and computer science have diverged. Some important attempts to synthesize the results of these distinct research traditions and coordinate their theoretical proposals have been attempted. Nicol and Swinney (1989) have argued that the structural restrictions on co-reference isolated in the linguistic literature act as a preliminary filter limiting a set of potential antecedents to assist in the resolution of a pronoun's antecedent. Matching of lexical, morphosyntactic features and other interpretative processes then further narrow these candidates. Badecker and Straub (2002) have provided some evidence against this temporal dissociation between structurally defined candidate sets and morphosyntactic candidate sets, suggesting instead that both factors operate simultaneously as constraints to narrow the set of potential antecedents of a pronoun. In our previous work (Gordon \& Hendrick, 1997, 1998), we have attempted a synthesis that makes both prominence in a discourse and matching of lexical, morphosyntactic features weakly sensitive to the structural position NPs occupy in an utterance. This paper examines the on-line comprehension of Mandarin Chinese pronominals using experimental measurement of reading times. Our goal is to evaluate how successfully the theories of pronoun resolution that have been previously proposed on the basis of English can generalize to the description of Chinese. We will show that the notion of discourse prominence and lexical feature matching are more sensitive to syntactic factors than was previously recognized. We will present evidence that prominence is sensitive to structural factors rather than grammatical functions or semantic roles. In this way we push further our synthesis of the distinct research programs surveyed above.

\subsection{The logic of the current study}

Past research suggests that the study of Chinese can contribute to the understanding of the mechanisms underlying language comprehension because of its similarities and differences with English and other European languages, which have provided most of the data for theory in psycholinguistics. For example, Huang and Hanley (1994) explored processes underlying word recognition by using special features of written Chinese, and Gelman and Tardif (1998) have explored generics and concept formation in Chinese. In the domain of sentence comprehension Li, Bates, and MacWhinney (1993) reported a reaction-time study of distinct sentence constructions to investigate how semantic roles are assigned to nominals in Chinese sentences. Here we attempt to exploit special properties of Chinese to probe the comprehension of pronominals. Although Chinese is historically unrelated to English and there is little in the way of morphological affixes on nouns or verbs, Chinese and English are broadly comparable because they share important clausal properties relevant to the understanding of pronominals.

Both Chinese and English have descriptions, names and overt pronouns. In both 
languages the distribution of these expressions is influenced by syntactic and discourse factors. However, unlike English, Chinese has phonologically unexpressed pronouns (i.e. null pronouns) that do not code morphosyntactic features such as gender (Li \& Thompson, 1981). Scholars of Chinese grammar have generally agreed that null pronouns occur quite often in both classical and modern Chinese texts (Li, 1985; Li, C.N., 1997; Li \& Thompson, 1984; Ma, 1898/1935; Wang, 1955). Early linguistic studies in Chinese anaphora differentiated overt and null pronouns by their semantic functions and pattern of distribution (Ma, 1898/1935; Wang, 1955). This general point of view continues in more contemporary linguistic analyses (Li, 1985; Li, C.N., 1997; Li \& Thompson, 1981, 1984) which have suggested that null pronouns are used primarily to co-refer with the most-focused referent in a discourse although the overt pronoun can be used for the same purpose in some contexts. Due to its lexical features such as gender and number, an overt pronoun has an advantage over a null pronoun in its ability to co-refer with a less prominent referent in a discourse representation that matches its lexical features (Yang, Gordon, Hendrick, \& $\mathrm{Wu}, 1999)$. In short, the null pronoun has been well recognized for its abundant use in classical and modern Chinese text. Furthermore, overt and null pronouns can often be used for the same purpose in a discourse, referring back to the most prominent referent in the preceding text.

Chinese and English also have similarities and differences with respect to word order. Both languages have the canonical sentence form of subject-verb-object (henceforth S-VO) for basic sentences where the subject is typically an agent and the object is typically a patient. ${ }^{3}$ This parallel can be seen in (4). Chinese offers variations on this canonical pattern. One resembles the passive construction in English in that the patient is mapped onto the initial subject position and the agent is optionally expressed as a complement of the oblique prepositional particle bei (被). This pattern is illustrated in (6). In addition, Chinese has some surface word order patterns unavailable in English. One such construction can be observed in the ba construction of (5). Here the theme of the verb, fang (放, put), appears as a complement of ba (把).

(4)

嘻三

放了一本

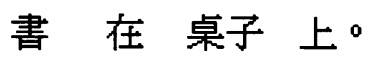

Zhangsan fang-le

yi-ben

shu zai zhuozi-shang.

\section{ZHANGAN PUT-PERFECT ONE-CLASSIFIER BOOK AT TABLE-TOP.}

\section{Zhangsan put a book on the table.}

\footnotetext{
${ }^{3}$ For expository convenience we have used the terms agent and patient throughout this paper. A host of other semantic roles can be found in the literature, and some might prefer to use some of these other terms to identify the semantic roles of nominals in some of the sentences we discuss. They include theme, experiencer, stimulus, goal and the like. See Dowty (1991) for a discussion of such semantic roles.
} 
(5) 張三 把 書放了 在 桌子 上。

Zhangsan ba shu fang-le zai zhuozi-shang

ZHANGSAN BOOK PUT-PERFECT AT TABLE-TOP

Zhangsan put the book on the table

(6) 書被 [張三〕放了在桌子 上。

shu bei (Zhangsan) fang-le zai zhuozi-shang

BOOK BY ZHANGSAN PUT-PERFECT AT TABLE-TOP

(7) $\mathbf{P}$<smiles>CCC</smiles>

NP<smiles>[3H][I-]C</smiles>

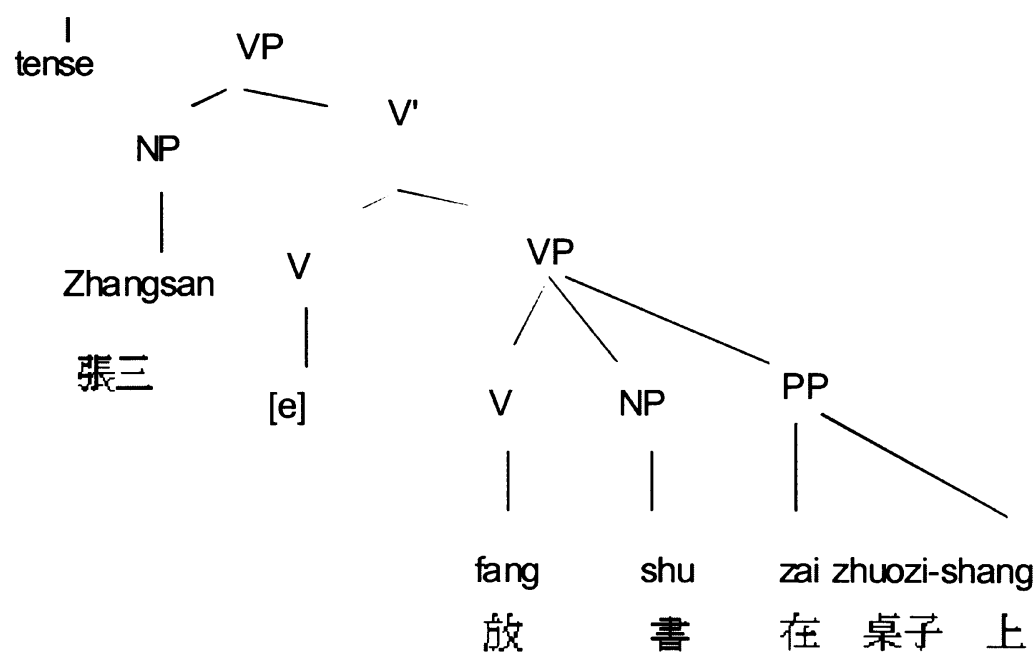

These distinct sentence constructions have been the focus of linguistic analysis (cf. Huang, 1982, 1994; Li, J.-I.J., 1997; Zou, 1992). We will assume here that the abstract structure of a Chinese sentence is as in (7). We will assume with Huang $(1994$, p. 162) that 
[v e] is a causative verb like make but without phonological expression. That verb can combine with the lexical verb fang (把, put) by syntactically raising fang, thus producing the sentence in (4). ${ }^{4}$ Alternatively, fang can remain in place and the dummy verb ba (把) can be inserted to replace [v e]. Updating slightly Huang's analysis, we assume that the direct object shu (書) will be promoted to become the direct object of ba. This raising is required to provide case to the direct object. ${ }^{5}$ This will generate the sentence in (5). The passive-like construction in (6) is produced by projecting the agent not onto the subject position, but onto an "oblique" position as the complement of the preposition bei (被). This bei phrase is an adjunct in the sense that it is only optionally present in a sentence and can be omitted. The patient of the verb in this construction comes to occupy the surface subject position rather than the canonical object position. ${ }^{6}$

If prominence is defined over semantic roles such as agent and patient we would expect all three sentences to have essentially the same influence on subsequent pronominal coreference. This expectation stems from the fact that all three sentences are synonymous to the extent that they have the same truth conditions (i.e. they are true or false in the same set of situations). Because they share the same predicates, they also share the same semantic roles that are linked to nominal expressions in the sentences. A very different prediction arises if prominence is characterized in terms of grammatical functions or in terms of phrasal structure. If prominence is defined in terms of grammatical functions such as subject and direct object, we expect sentences (4) and (5) to have the same influence on subsequent pronominal co-reference. This is because they only differ in the surface positioning of NPs; crucially the grammatical functions that each NP serves are the same. Sentence (6) should behave differently because the NPs have changed their grammatical function from the canonical construction in (4). On the other hand, if prominence is defined structurally we expect (4) and (5) to have different effects on subsequent coreference because, even though the grammatical functions are the same, the hierarchical organizations of the sentences are distinct: in (4) the object is in the complement of the (raised) verb; in (5) the object is in the specifier position of the (unraised) verb.

The experiments in this paper test these competing claims about the fundamental nature of prominence in a discourse with a series of experiments that examine how the comprehension of pronominals is modulated by the structure of the three types of sentences illustrated in (4)-(6). Table 1 provides a sample passage illustrating the experimental manipulations that we used. One manipulation was the word order of the first sentence (Canonical, BA, or BEI constructions). A second manipulation was the discourse relationship of the second sentence with the first sentence (continue vs. shift). As the connecting lines in Table 1 illustrate, the continue condition leads the pronominal to co-refer to the leftmost named character of the initial sentence. The shift condition forces the pronominal to co-refer to the rightmost name in the initial sentence.

In addition to the manipulation of discourse relations and of prominence through the

\footnotetext{
${ }^{4}$ Another structure that we will not discuss here copies fang in the high $[\mathrm{v}$ e] position so that fang appears in both verbal positions.

${ }^{5}$ The subject raises to receive case from the I element that contains temporal information for similar reasons.

${ }^{6}$ In some theories the patient is initially projected as the direct object, and subsequently raises to become the subject of the sentence. Other theories have mechanisms that project the patient directly onto the subject position.
} 
Table 1

A prototypical sample passage illustrating the kinds of stimuli used in Experiments 1 through $4^{\mathrm{a}}$

\section{Canonical and BA Structure}

1. Initial Sentence

Canonical $\left(\mathrm{N}_{\mathrm{sut}} \vee \mathrm{N}_{\mathrm{obi}}\right)$

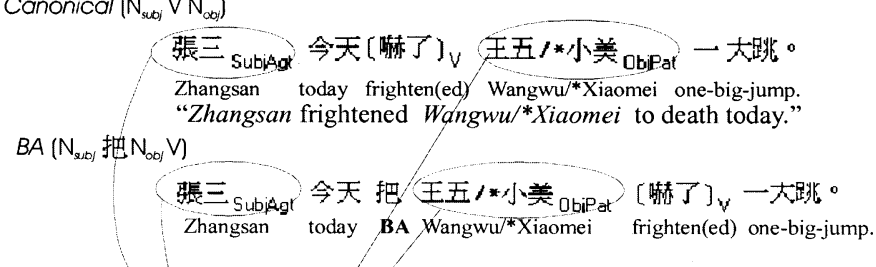

2. Second Sentence (for Canonicál and BA orders)

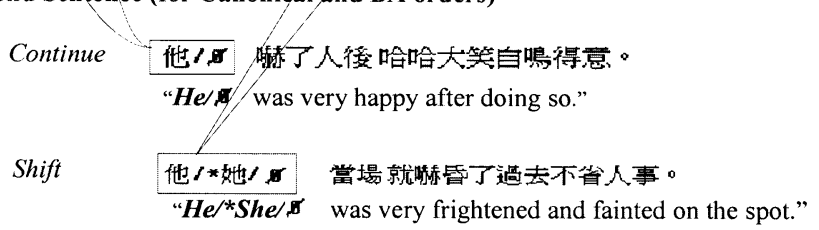

\section{BEI Structure}

1. Initial Sentence

$B E I\left(\mathrm{~N}_{\text {ob }}\right.$ 被 $\left.\mathrm{N}_{\text {subj }} \mathrm{V}\right)$

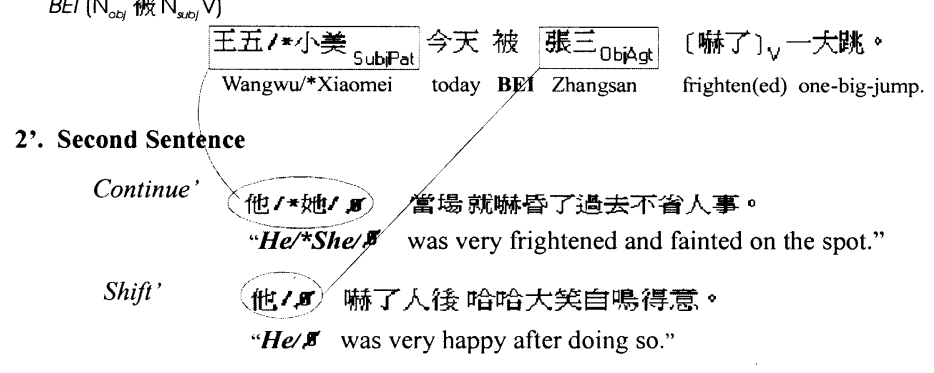

\section{Passage-final Sentence}

随便墑哧人是一件很要不得的行蒚。

"Playing tricks is not supposed to go as far as this."

\footnotetext{
${ }^{a}$ The operational definition of the discourse relationship, continue vs. shift, is based on the syntactic mapping of the discourse entities across sentences. The continue condition has the grammatical subject of the second sentence co-referring with the grammatical subject of the first sentence while the shift condition has the grammatical subject of the second sentence co-referring with the grammatical object of the first sentence. This results in two instantiations of the second sentence for each experimental passage, either of which could follow the first sentence. The genders of the two named characters are either the same or different across experiments. For example, in the first sentence, the grammatical subject Zhangsan ( $\mathrm{GE}_{\mathrm{E}} \mathrm{Z}_{\text {SubjAgt }}$ ) is a male while the gramma-

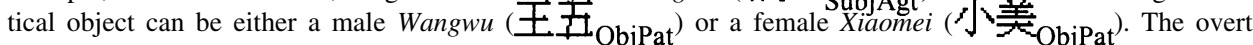
pronoun of the second sentence can either unambiguously or ambiguously indicate its intended referent in the model of discourse. Of course, the null pronoun is necessarily ambiguous.
} 
structure of the first sentence, we also manipulated the type of referring expression in the second sentence. This was done so as to provide evidence about whether the set of potential antecedents for a pronoun is narrowed exclusively by prominence characteristics, defined either in syntactic or semantic terms, or whether this candidate set is also delimited early in processing by lexical feature matching. If prominence features are exploited early, and independently from lexical feature matching, we should find a difference in the ease of interpreting pronouns following sentences (4)-(6) regardless of whether the nominals lexically match the pronouns to be interpreted. On the other hand, if matching operates early in processing we would expect it to interact with the identification of potential antecedents in (4)-(6), so that the differences in ease of comprehension in (4)-(6) might be eliminated when lexical features identify a single potential antecedent. To examine this, the gender of the two named characters in the first sentence could either be the same gender or different gender. This manipulated whether co-reference for the pronominal expressions in the second sentence was ambiguous or unambiguous. In addition, different forms of pronominal expressions (overt/null pronoun) were realized for the grammatical subject of the second sentence across different experiments.

The comparisons outlined in Table 1 provide a very rich source of potential evidence about the nature of discourse prominence and how it interacts with feature matching in the comprehension of pronominals. However, the relations in Table 1 are too complex to be pursued in a single experiment. The four experiments presented below focus on those comparisons of conditions that can provide the greatest evidence about these questions.

\section{Experiment 1}

This experiment examined whether syntactic factors (either structural relations or grammatical functions) or semantic roles modulate the process of pronominal resolution. Nominal expressions in a sentence are provided with three types of information in most linguistic theorizing: structural status, grammatical function, and semantic role. They are syntactically assigned a structural (or categorial) status (as an NP). In addition they stand in a syntactic relation to the predicate; this is the basis for recognizing a set of grammatical functions such as subject, direct object, etc. Nominal expressions are also provided with a semantic role such as agent, patient and the like. The experiment manipulated two variables: word order for the first sentence (Canonical vs. BEI) and the discourse relationship of the second sentence with the first sentence (continue vs. shift). This design allowed us to hold the semantic roles of the nominals in the first sentence constant while we manipulated the mapping of those semantic roles onto syntactic positions. We used a self-paced reading task to examine the on-line processing when participants read passages such as the one shown in Table 2.

According to Gordon et al. (1993) and Yang et al. (1999), the comprehension of pronominal expressions is modulated by the syntactically-derived accessibility of discourse referents in the model of discourse. The results of Yang et al. (1999) suggested that similar results could be found in Chinese. That work explored the comprehension of the canonical word order. In this experiment we manipulated the word order between the canonical word order and the passive-like BEI structure. We employed experimental 
Table 2

The sample stimuli for Experiment $1^{\mathrm{a}}$

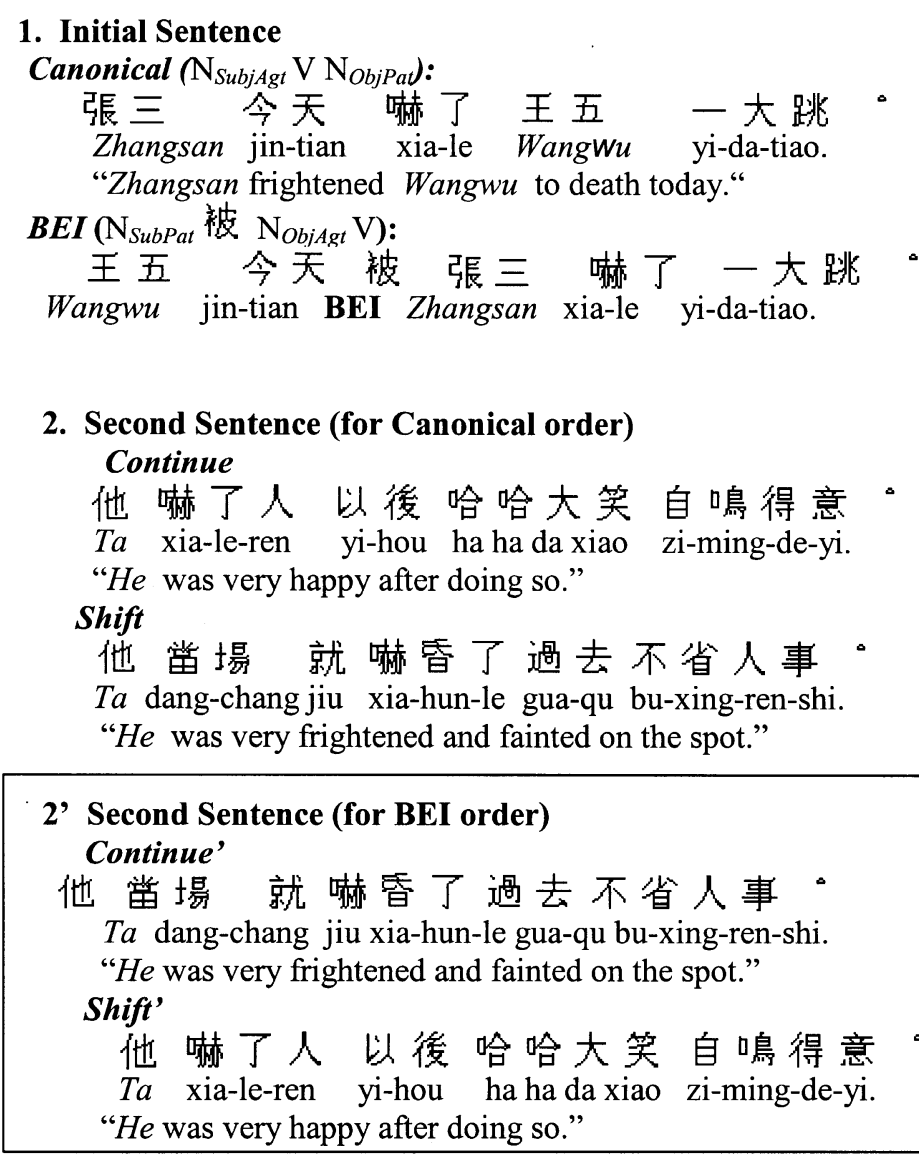

\section{Passage-final Sentence}

鲛嚇人是一件很要不得的行為。

luao-xia-ren shi yi-jian heo yao-bu-de di xing-wei

"Playing tricks is not supposed to go as far as this."

\footnotetext{
a The passage was three sentences long. The two named characters introduced in the initial sentence have the same gender. The grammatical subject Zhangsan (菲三) and the grammatical object Wangwu (王开) are conventionally male names. This creates a situation of ambiguous co-reference for the subject pronoun of the second sentence where the gender of such pronominal anaphor does not facilitate the identification of the intended referent in the model of discourse. For this and the following experiments, all the Chinese sample stimuli reported in this paper adopted the system of "Hanyupinyin" (Wentzu Kaiko Chupanshe, 1958) for the pinyin spellings.
} 
passages which contained two named characters of the same gender introduced by the initial sentence. In this way, the grammatical subject of the second sentence was an overt pronoun with ambiguous co-reference; its gender feature could not be used to pick out the intended referent directly in the model of discourse by identifying a unique referent that matched in gender. With this design, the contrast of the canonical and BEI structures provides an opportunity to test whether the syntactic relations or the semantic role of potential antecedents of a pronoun modulate pronoun resolution.

\subsection{Method}

\subsubsection{Participants}

Forty participants, all native speakers of Mandarin Chinese enrolled in Introductory Psychology at the National Taiwan University (NTU), were tested in the experiment. For their participation they received credit toward the fulfillment of a course requirement.

\subsubsection{Stimuli}

The stimuli, design, and procedure were similar to that of Yang et al. (1999), both for this experiment and the following ones in this paper. A set of 32 three-sentence passages like the one shown in Table 2 was constructed. There were four versions of each experimental passage constructed by varying the word order of the first sentence (Canonical and $\mathrm{BEI}$ ), and two kinds of relationships between the second and the first sentences (continue and shift). There were two named characters introduced in the first sentence whose names were conventionally of the same gender. The gender sequence for the two characters in the first sentence of each passage was balanced across passages so that half of the passages were male-male and half were female-female. The subject of the second sentence of the passage was either the first named character for the continue condition or the second named character for the shift condition; the second sentence did not mention the other character. The number of words in the second sentence was matched in the continue and shift conditions in this experiment and in the subsequent experiments. The third sentence of the passage did not mention either character. A set of 88 filler passages was composed for the experiment. Like the experimental passages, the filler passages were three sentences long and included named characters and pronominal reference. However, the filler passages contained grammatical forms that were not present in the experimental passages so as to increase the variety of the passages that participants read. A true-false comprehension question was constructed for every passage. Correctly answering the question required knowledge of the event described in the passage but did not depend on knowledge of the names of the characters.

\subsubsection{Design and procedure}

Four versions of each experimental passage were devised and each was assigned to one of four sets of materials. The 32 experimental passages in each material set were grouped in 88 filler passages to create five experimental blocks of 24 passages each. In each block, there were approximately six to seven experimental passages as well as 17 or 18 filler passages. In this design, each experimental passage was presented to a participant in only one condition, and across participants every passage occurred in all conditions. The 
passages were grouped into an initial warm-up block of 20 filler passages that served to familiarize participants with the task. Passages were presented one sentence at a time at the center of the computer screen, and participants pressed the space bar in order to advance to the next sentence. Participants were instructed to read each sentence at a natural pace. After each passage the true-false question was presented and participants were given immediate feedback about the accuracy of their responses. The experimental passages within a block were presented in a different random order for each participant.

\subsection{Results}

Fig. 1 shows the mean reading time for the second, critical sentence as a function of the experimental manipulations. Reading times below $450 \mathrm{~ms}$ per sentence or above $4800 \mathrm{~ms}$ were considered to be premature or careless responses and were excluded as outliers from the analyses; they comprised $3.9 \%$ of the data. Reading times for the second sentence were faster in the continue condition than in the shift condition, regardless of the word order (Canonical or BEI) in the first sentence. Analysis of variance (ANOVA) was used to assess the generality of the results both by participants $\left(F_{1}\right)$ and by items $\left(F_{2}\right)$. Only the main effect of continue vs. shift reached statistical significance both by participants $\left(F_{1}(1,39)=22.70, P<0.001\right)$ and by items $\left(F_{2}(1,31)=15.18, P<0.001\right)$. There was a trend in the direction of longer reading times for the BEI word order as compared to the canonical word order, but this effect was short of significance $\left(F_{1}(1,39)=2.49\right.$, $\left.P=0.123 ; F_{2}(1,31)=1.41, P=0.245\right)$. The interaction of continue and shift with word order was not significant $\left(F_{1}(1,39)=1.19, \quad P=0.282 ; \quad F_{2}(1,31)=0.65\right.$, $P=0.426)$. For the comprehension questions, mean accuracies were: Canonical-continue (87.8\%), Canonical-shift (86.4\%), BEI-continue (85.0\%), and BEI-shift (87.9\%). Statistical analysis showed that experimental manipulations did not significantly influence accuracy.

\subsection{Discussion}

The results of this experiment showed consistent patterns of reading time differences between the continue and shift conditions for the second sentence regardless of the different kinds of word orders for the initial sentence. The reading time of the second sentence was shorter in the continue condition than in the shift condition regardless of whether the word order of the initial sentence was canonical or BEI structure. This pattern is consistent with our earlier findings in Yang et al. (1999, Experiment 3). Moreover, the results demonstrated that the effect of syntactic prominence (as instantiated by the difference between subject and direct object) is a primary factor in the processing of co-reference in Chinese and that it is independent of which semantic roles are mapped onto the subject and object positions. ${ }^{7}$ In this respect the comprehension of Chinese parallels what has previously been shown in English (Gordon \& Chan, 1995). The results support the idea that the syntactic structure of language influences the processing of referential interpretation by determining the accessibility of discourse referents in the model of discourse. It

\footnotetext{
${ }^{7}$ To avoid this conclusion one could try to posit an ordering of semantic roles independent of phrasal hierarchies or grammatical hierarchies. See for example Williams (1994).
} 
Ambiguous coreference for overt pronouns

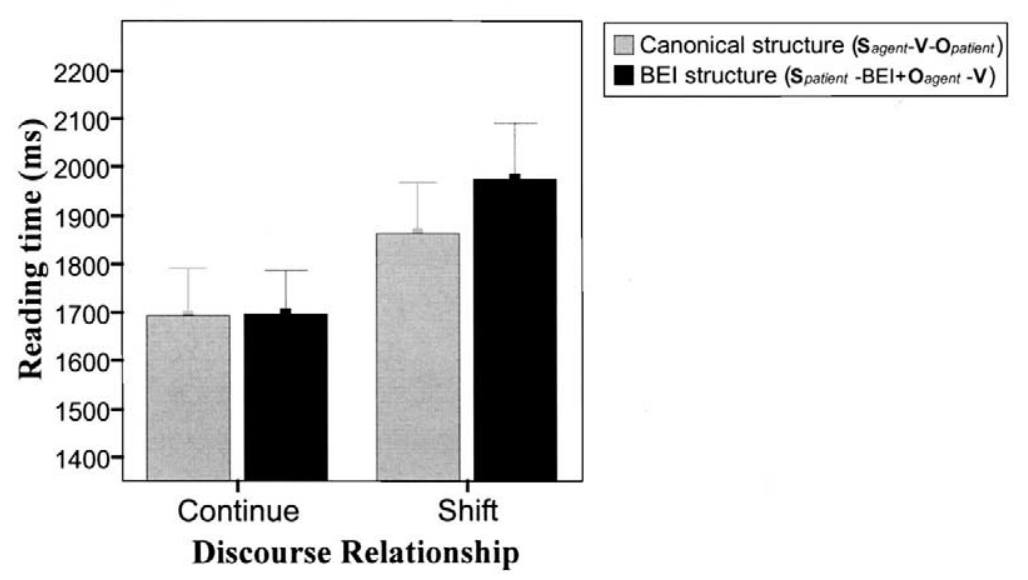

Fig. 1. Mean reading times (ms) of the second sentences in Experiment 1 as a function of the experimental manipulations in Experiment 1. Error bars show the 95\% confidence interval of the mean.

does not allow us to conclude which properties of syntactic structures are responsible for this result, or how they interact with lexical properties of pronominal expressions. For example, it could be that the hierarchical organization of an utterance is the principal factor determining the accessibility of a nominal, as we have proposed in Gordon and Hendrick (1998). Alternatively, one might imagine that linear order alone is a sufficient criterion for determining accessibility or that accessibility is the product of whether a nominal represents a privileged grammatical function such as subject. ${ }^{8}$ We will address below the issue of whether being first hierarchically or in linear order is the main factor determining accessibility.

\section{Experiment 2}

Experiment 1 introduced a situation with ambiguous co-reference for the subject pronoun of the second sentence, and demonstrated that the comprehension of an overt pronoun was modulated by the accessibility of discourse referents as determined by their syntactic relations. The current experiment investigates how lexical features, particularly gender, contribute to the processing of pronominal resolution during discourse integration. According to Gordon and Hendrick (1998) and Yang et al. (1999), co-reference to an antecedent of low prominence is facilitated during discourse integration when the gender feature of a pronominal expression provides effective cues to uniquely identify its intended referent. The present study examines whether this effect interacts with the manipulation of syntactic word order. Like Experiment 1, this experiment manipulated two variables: the

\footnotetext{
${ }^{8}$ This dichotomy between hierarchical order and linear order would not arise if one were to adopt the theory of structural organization outlined in Kayne (1994) where hierarchical order is a function of linear order.
} 
word order for the first sentence (Canonical vs. BEI) and the discourse relations (continue vs. shift). The two named characters introduced in the first sentence were of different genders. The grammatical subject of the second sentence was an overt pronoun with unambiguous co-reference. Therefore, its gender feature could unambiguously indicate the suitable referent that matched its gender. The question was whether this unambiguous match facilitates pronoun resolution and the integration of the semantics of the second sentence with the semantics of the discourse model. We used the self-paced reading task to examine the reading of passages such as the one shown in Table 3.

\subsection{Method}

\subsubsection{Participants}

Forty-eight new students from the same population as the previous experiment participated in this study.

\subsubsection{Stimuli, design, and procedure}

The set of 32 three-sentence passages used in Experiment 1 was adapted for this study. Appropriate changes were made to the initial sentence of each passage in terms of the gender of the two characters, and to the second sentence with regards to the gender of the pronominal expressions used. The experiment was conducted in the same manner as that in Experiment 1 in terms of the assignment of experimental passages to conditions, participants, and trial blocks.

\subsection{Results}

Fig. 2 shows the mean reading times for the critical sentence as a function of the experimental manipulations. Outliers, defined as before, comprised $2.7 \%$ of the data. The results indicated that when the first sentence had canonical structure, the reading time for the continue condition was as fast as that in the shift condition. In contrast, when the first sentence used the BEI structure, the reading time for the continue condition was faster than that in the shift condition. ANOVA further showed that neither the main effect of word order (Canonical vs. BEI) $\left(F_{1}(1,47)=0.64, P=0.427 ; F_{2}(1,31)=0.37\right.$, $P=0.549)$ nor the main effect of discourse relation (continue vs. shift) $\left(F_{1}(1,47)=1.64\right.$, $\left.P=0.207 ; F_{2}(1,31)=1.24, P=0.275\right)$ were significant. The interaction of word order and discourse relation reached statistical significance by participants $\left(F_{1}(1,47)=5.56\right.$, $P<0.05)$ and by items $\left(F_{2}(1,31)=5.32, P<0.05\right)$. Contrasts showed that the effect of continue vs. shift was not significant when the first sentence had the canonical order $\left(t_{1}(47)=0.88, P>0.5 ; t_{2}(31)=0.85, P>0.5\right)$, while the difference between the conditions was significant when the first sentence contained the BEI structure $\left(t_{1}(47)=2.46\right.$, $\left.P<0.01 ; t_{2}(31)=2.37, P<0.05\right)$. The mean accuracies for comprehension questions were: Canonical-continue (92.3\%), Canonical-shift (92.0\%), BEI-continue (92.2\%), and BEI-shift $(89.5 \%)$. Statistical analysis indicated that the experimental manipulations did not significantly affect accuracy. 
Table 3

The sample stimuli for Experiment $2^{\mathrm{a}}$

\section{Initial Sentence}

Canonical $\left(\mathrm{N}_{\text {Subjagt }} \mathrm{V} \mathrm{N}_{\text {ObjPat }}\right)$ :

張三今天嚇了小美 一大跳

Zhangsan jin-tian xia-le Xiaomei yi-da-tiao.

"Zhangsan frightened Xiaomei to death today."

BEI $\left(\mathrm{N}_{\text {SubPat }}\right.$ 被 $\left.\mathrm{N}_{\text {Objagt }} \mathrm{V}\right)$ :

小美今天被張三嚇了一大跳

Xiaomei jin-tian BEI Zhangsan xia-le yi-da-tiao.

\section{Second Sentence (for Canonical order)}

Continue

他嚇了人以後哈哈大笑自鳴得意

Ta xia-le-ren yi-hou ha ha da xiao zi-ming-de-yi.

"He was very happy after doing so."

Shift

她苗場就嚇聙了過去不省人事。

Ta dang-chang jiu xia-hun-le gua-qu bu-xing-ren-shi.

"He was very frightened and fainted on the spot."

\section{2' Second Sentence (for BEI order)}

Continue'

她炎場就嚇電了過去不省人事。

Ta dang-chang jiu xia-hun-le gua-qu bu-xing-ren-shi.

"He was very frightened and fainted on the spot."

Shift'

他嚇了人以後哈哈大笑自鳴得意

Ta xia-le-ren yi-hou ha ha da xiao zi-ming-de-yi.

"He was very happy after doing so."

\section{Passage-final Sentence}

销嚇人是一件很要不得的行為。

luao-xia-ren shi yi-jian heo yao-bu-de di xing-wei

"Playing tricks is not supposed to go as far as this."

\footnotetext{
a The two named characters are different genders. The grammatical subject Zhangsan (䔍三) is a male name, and the grammatical object Xiaomei (小美) is a female name. Thus, the pronominalization of grammatical subjects of the second sentence varies in different conditions of discourse relationship. This introduced a situation of unambiguous co-reference for the subject pronoun of the second sentence where the gender of such pronominal anaphor facilitates the identification of the intended referent in the model of discourse.
} 


\subsection{Discussion}

The results of this experiment indicated that when the first sentence had the canonical structure, and when the gender feature of the subject pronoun unambiguously picked out its referent from the two names introduced by the first sentence of the passage, there was no reading time difference across the continue/shift conditions for the second sentence. This pattern is consistent with what has been found in previous studies (Yang et al., 1999, Experiment 4). What the current experiment adds to this picture is that the effect varies with the word order of the initial sentence. When the first sentence was the BEI structure, the reading times of the second sentences were faster in the continue condition than in the shift condition. Linguistic analysis suggests that the semantic agent in a structure with passive voice is mapped syntactically onto an adjunct structure that bears an oblique grammatical function, a position that is optional and that has little prominence. We infer that in the BEI structure, where the complement of bei (the semantic agent) has a much lower degree of syntactic prominence than that of the grammatical object in the canonical structure, even the gender of an unambiguous overt pronoun cannot facilitate the processing of a referent of low accessibility. Overall, the results of the current experiment, along with those of Experiment 1, support the claim that the syntactic organization of an utterance plays a primary role to guide the mapping of discourse entities into the model of discourse. This, in turn, determines the accessibility of discourse referents in a model of discourse for subsequent processing of referential interpretation such as pronoun resolution. Lexical matching also plays a significant role in this process. Moreover, it is influenced by the prominence of the potential antecedents.

\section{Experiment 3}

Experiment 1 showed that the accessibility of a nominal as a candidate antecedent for a

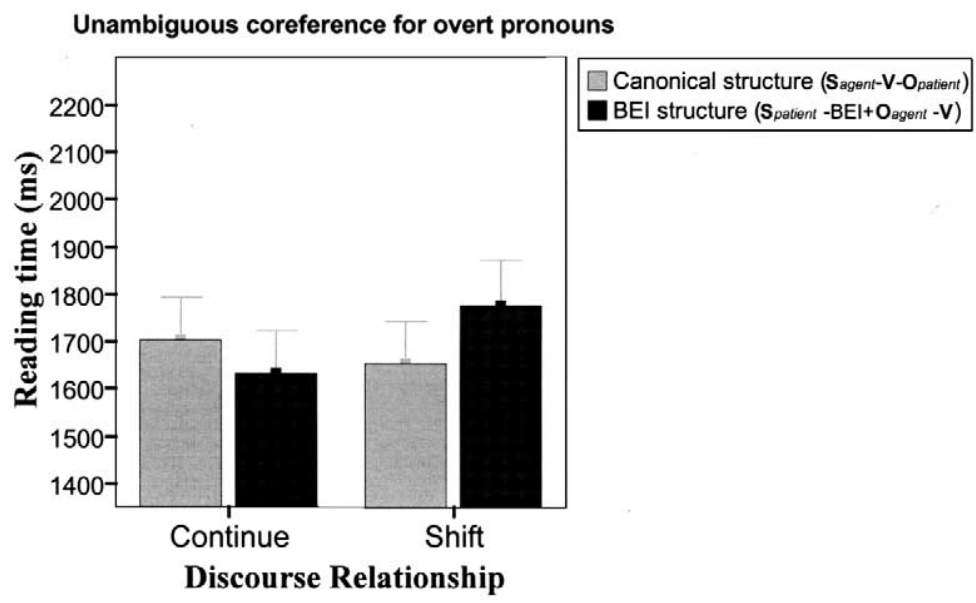

Fig. 2. Mean reading times (ms) of the critical sentences in Experiment 2 as a function of the experimental manipulations. Error bars show the $95 \%$ confidence interval of the mean. 
pronominal was a function of a syntactically-derived notion of prominence rather than one based on semantic roles. Prominence of this kind had a direct impact on sentence comprehension, making the shift condition more difficult than the continue condition for both the Canonical and the BEI construction. Experiment 2 suggested that this effect of prominence was present only when the antecedent of a pronominal was ambiguous: when gender information unambiguously identified an antecedent there was no significant contrast in the comprehension of continue and shift sentences. Our third experiment is designed to investigate further how the prominence of a discourse referent is influenced by the syntactic organization of an utterance. In the current experiment, the first sentence had three alternative word orders: Canonical, BA and BEI. The two named characters in the first sentence were always of the same gender. The second sentence exhibited two kinds of discourse relations with the first sentence: continue and shift. The grammatical subject of the second sentence was realized as an overt pronoun with ambiguous co-reference. That is to say, the gender of such pronominal expressions could not uniquely identify its intended referent in the model of discourse. In this design, the three alternative versions of the first sentence could potentially induce different degrees of accessibility for the second NP. The overt pronoun with ambiguous co-reference in the second sentence provided the opportunity to test whether the second NP in the first sentence varied in its accessibility as a potential antecedent for that overt pronominal.

If accessibility were determined by some hierarchy of grammatical relations we would expect the canonical word order and the BA structure to affect pronoun interpretation in the same way because in both structures the second NP is a direct object. The BEI structure would be expected to cause different effects because the second NP would have an oblique grammatical relation (i.e. neither subject nor direct object). If, on the other hand, the accessibility of a nominal as an antecedent for a pronoun is determined by the linear or hierarchical organization of the sentence, different predictions are generated. For example, according to the Gordon and Hendrick (1998) model of discourse processing, the second NP in all three structures should have the same effect because that NP is always more deeply embedded in the phrasal hierarchy than the first NP. Experiment 3 examines this prediction measuring the reading time for passages such as the one shown in Table 4.

\subsection{Method}

\subsubsection{Participants}

This experiment tested 72 participants, all of whom were native speakers of Mandarin Chinese enrolled in Introductory Psychology at the National Cheng-Chi University (NCCU). Participants were paid for their participation.

\subsubsection{Stimuli, design, and procedure}

A set of 30 three-sentence passages, taken directly from the experimental passages of previous experiments, was used in the experiment. Appropriate changes were made for the initial sentence of each passage in terms of the word orders, and for the second sentence with regards to the gender and form of the pronominal expressions used. There are six alternative versions of each experimental passage made by varying the word orders of the initial sentence (Canonical, BA or BEI), and the discourse relationship of the second 
Table 4

The sample passage of Experiment $3^{\mathrm{a}}$

\section{Initial Sentence}

Canonical $\left(\mathrm{N}_{\text {Subjagt }} \mathrm{V} \mathrm{N}_{\text {ObjPat }}\right)$ :

張三今天嚇了王五 一大跳

Zhangsan jin-tian xia-le Wangwu yi-da-tiao.

"Zhangsan frightened Wangwu to death today."

$\boldsymbol{B} \boldsymbol{A}\left(\mathrm{N}_{\text {Subjagt }}\right.$ 把 $\left.\mathrm{N}_{\text {ObjPat }} \mathrm{V}\right)$ :

張三今天把王五嚇了一大跳

Zhangsan jin-tian BA Wangwu xia-le yi-da-tiao.

BEI $\left(\mathrm{N}_{\text {SubPat }}\right.$ 被 $\left.\mathrm{N}_{\text {ObiAgt }} \mathrm{V}\right)$ :

王五 今天被張三嚇了一大跳

Wangwu jin-tian BEI Zhangsan xia-le yi-da-tiao.

\section{Second Sentence (for Canonical and BA order)}

\section{Continue}

他嚇了人以復哈哈大笑自鳴得意

Ta xia-le-ren yi-hou ha ha da xiao zi-ming-de-yi.

"He was very happy after doing so."

Shift

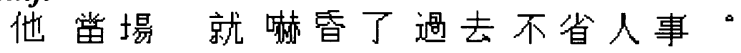

Ta dang-chang jiu xia-hun-le gua-qu bu-xing-ren-shi.

"He was very frightened and fainted on the spot."

\section{2' Second Sentence (for BEI order)}

Continue,

他崖場就嚇筸了過去不省人事。

Ta dang-chang jiu xia-hun-le gua-qu bu-xing-ren-shi.

"He was very frightened and fainted on the spot."

Shift'

他嚇了人以後哈哈大笑自鳴得意

Ta xia-le-ren yi-hou ha ha da xiao zi-ming-de-yi.

"He was very happy after doing so."

\section{Passage-final Sentence}

嘀嚇人是一件很要不得的行堂。

luao-xia-ren shi yi-jian heo yao-bu-de di xing-wei

"Playing tricks is not supposed to go as far as this."

\footnotetext{
${ }^{\text {a }}$ The initial sentence has three alternative versions of word orders (Canonical/BA/BEI). The two named characters are of the same genders in that the grammatical subject Zhangsan (䔍三) and the grammatical object Wangwu (王开) are conventionally male names. This introduced a situation of ambiguous co-reference for the subject pronoun of the second sentence where the gender of such pronominal anaphor does not facilitate the identification of the intended referent in the model of discourse.
} 


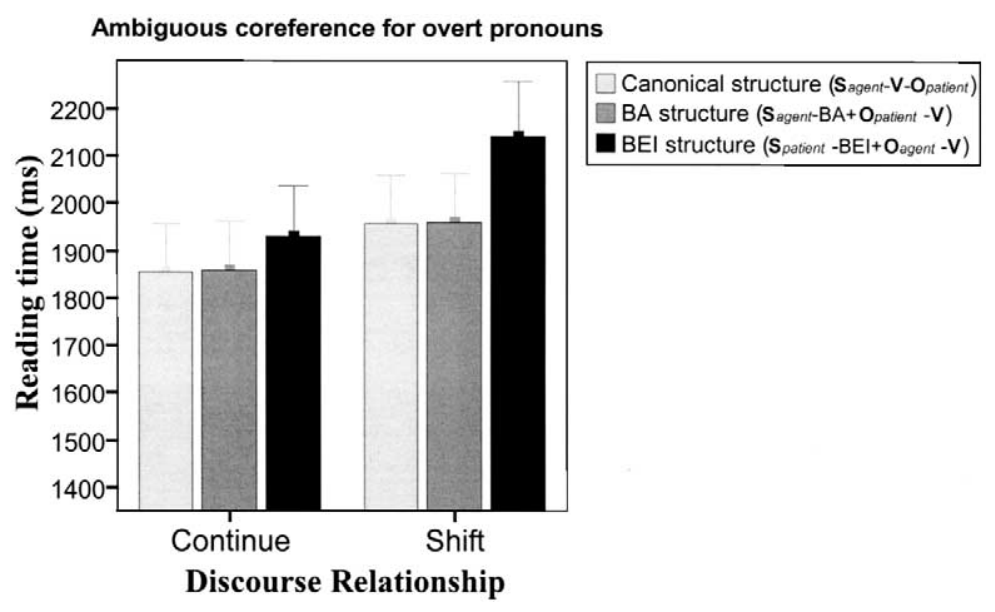

Fig. 3. Mean reading times (ms) of the critical sentences in Experiment 3 as a function of the experimental manipulations. Error bars show the $95 \%$ confidence interval of the mean.

sentence with the initial sentence (continue vs. shift). Six sets of stimuli material for experimental passages were constructed. In addition, a set of 90 filler passages adopted from the filler passages of previous experiments was employed in this experiment. Each stimulus material set was grouped with 90 fillers to create five experimental blocks with 24 passages each. All other aspects of design, procedure and conduction of the experiment were similar to those in preceding experiments.

\subsection{Results}

Fig. 3 shows the mean reading times for the critical sentence as a function of experimental conditions. Based on the examination of the distribution of the data, reading times below $450 \mathrm{~ms}$ per sentence or above $5700 \mathrm{~ms}$ were considered to be premature or careless responses and were excluded as outliers from the analyses. ${ }^{9}$ Outliers comprised $2.6 \%$ of the data. The reading times for the continue condition were faster than those for the shift condition $\left(F_{1}(1,71)=10.18, P<0.01 ; F_{2}(1,29)=11.37, P<0.01\right)$. The main effect of word order (Canonical, BA or BEI) was also significant $\left(F_{1}(2,142)=5.54, P<0.01\right.$; $\left.F_{2}(2,58)=3.22, P<0.05\right)$. Contrasts showed that there was no significant difference in the times for the Canonical and BA conditions $\left(t_{1}(71)=0.04, P>0.5 ; t_{2}(29)=0.03\right.$, $P>0.5)$ but that the average of the Canonical and BA conditions was faster than the BEI condition $\left(t_{1}(71)=3.33, P<0.001 ; t_{2}(29)=2.58, P<0.01\right)$. The interaction between the word order and the continue/shift was not significant by participants $\left(F_{1}(2,142)=0.88, P=0.418\right)$, or by items $\left(F_{2}(2,58)=0.28, P=0.760\right)$. The mean accuracies for comprehension questions were: Canonical-continue (91.0\%), Canonical-

\footnotetext{
${ }^{9}$ The upper boundary for excluding outliers was expanded in this experiment, as compared to the other experiments (Experiments 1, 2 and 4) because the reading time for the critical sentence in Experiment 3 was longer (average of $2032 \mathrm{~ms}$ ) than in the other three experiments (averages of 1938, 1797 and 1850, respectively).
} 
shift $(82.8 \%)$, BA-continue (86.7\%), BA-shift (85.6\%), BEI-continue (86.3\%), and BEIshift $(86.7 \%)$. Accuracy was not significantly modulated by the experimental manipulations.

The finding of significantly slower reading times following the BEI word order contrasts with the absence of a significant difference between reading times following the BEI and Canonical word orders in Experiment 1; differences in that experiment were in the same direction but were not significant. In order to better understand whether there is an effect of Canonical vs. BEI word order, an ANOVA was performed combining results from the Canonical and BEI conditions of Experiments 1 and 3. Word order (Canonical vs. BEI) was a within-subjects variable while Experiment (1 vs. 3) was a between-subjects variable. The results showed that for the combined experiments, reading times were significantly slower following the BEI structure than following the Canonical structure $\left(F_{1}(1,110)=7.73, P<0.01 ; F_{2}(1,60)=8.01, P<0.01\right)$. The interaction between word order and experiment was not significant $\left(F_{1}(1,110)=0.37, \quad P>0.25\right.$; $\left.F_{2}(1,60)=1.04, P>0.25\right)$.

\subsection{Discussion}

There was a consistent pattern of reading time differences between the continue and shift conditions across the three different kinds of word orders for the first sentence: the second sentence was read faster in the continue condition than in the shift condition. This overall continue/shift effect is consistent with the prediction that the accessibility of a name as an antecedent for a pronoun is influenced by its syntactic prominence. Furthermore, this finding bears on the correct characterization of how syntactic organization influences pronoun resolution during sentence comprehension. If grammatical functions determine the prominence of a name, direct objects should have the same accessibility as antecedents in both the canonical word order and the BA structure. The results of this experiment are consistent with that prediction. At the same time the findings are problematic for the structural algorithm that determines prominence in Gordon and Hendrick (1998). That model would assign lower prominence to the second name relative to the first name. It gives this result regardless of the grammatical function of the second name and makes no distinction as the second name appears in increasingly embedded structures. The difficulty is that the second name in each of the structures probed in this experiment did not have a uniform degree of accessibility as antecedents in the shift condition. The difference between the BEI structure and the other two structures is unexpected from this perspective. This difference was not statistically significant in Experiment 1, but the combined analysis of the results of Experiments 1 and 3 show that it is robust.

In our discussion of Experiment 1 we noted that the results of that experiment were inconsistent with an explanation in terms of semantic roles, and could only be explained by the appeal to syntactic factors: either to the grammatical categories in the stimuli or to the structural organization of the stimuli, as in Gordon and Hendrick (1998), or possibly to the linear order of the stimuli. The present experiment allows us to draw an inference about whether linear order is the primary cue responsible for the prominence of an element. We see two ways of making explicit the appeal to linear order. If left-to-right order of only nominals is the relevant consideration, each of the three Chinese orders (Canonical, BA 
and BEI structures) should give the same continue/shift patterns. If left-to-right order relative to nominals and verbs (and perhaps other lexical items as well) was the relevant consideration, all three orders should give distinct patterns simply because each has a distinct linearization in the relevant sense. Neither prediction is corroborated by the findings in Experiment 3. The processing of sentences following the BEI structure differed from that of the Canonical and BA structures which produced the same results. For this reason, we infer that linear order, dissociated from phrasal organization, cannot be the exclusive cue for determining prominence.

\section{Experiment 4}

Experiments 1 and 2 contrasted the canonical word order and the BEI structure in an attempt to examine how the syntactic prominence of a discourse entity and lexical features, such as gender, modulated subsequent processing of pronominal resolution during discourse integration. The results indicated that the comprehension of pronominal expressions was primarily modulated by the syntactically-derived accessibility for discourse referents in the model of discourse. In addition, the lexical features of a pronominal expression (e.g. gender) facilitate processing when they can serve as an effective cue to unambiguously identify a pronoun's antecedent. These effects were more pronounced as the prominence of the antecedent increased. Building on these results, Experiment 3 was designed to examine the proper characterization of syntactic prominence. The issue we set out to examine was whether prominence is a result of grammatical functions (such as subject and direct object) or whether it is more closely tied to the hierarchical organization of phrases in a syntactic structure. This is a common distinction in theoretical linguistics, but it has not been explored in psycholinguistic work. We found that the Canonical and the BA structures were not significantly different in the effect they had on pronoun resolution in the continue/shift conditions. The BEI structure differed by causing subsequent sentences to be read more slowly.

Theories based on grammatical functions such as the Lexical Functional Grammar of Bresnan (2001) treat null pronouns in languages that lack agreement morphology, like Chinese, as a grammatical function which is given a semantic value but which is not associated with any NP in the syntactic structure. In other words the grammatical function is disassociated from any structural category and is interpreted semantically on its own. This provides an ideal situation in which to test the contribution of grammatical functions to prominence. If prominence were defined on grammatical functions exclusively, replacement of the phonologically overt pronoun in Experiment 3 with an understood, phonologically null pronoun should have no impact on the calculation of prominence. We would expect to find the same pattern of results that we found in Experiment 3.

To test this claim we build on an important finding about overt and phonologically null pronouns in Chinese. Using the same type of reading time experiments as reported in this article, Yang et al. $(1999,2001)$ demonstrated that there was no significant difference between overt and phonologically null pronouns when the first sentence had the Canonical structure; both showed comparable, significant continue/shift effects. We take this important finding to be a touchstone and build on it in our next experiment, Experiment 4. 
Knowing that overt and phonologically null pronouns were non distinct in the Canonical structure, we designed our fourth experiment to complete our knowledge of the interaction of phonologically null pronouns with the three Chinese sentence patterns that are the focus of this article. Experiment 4 used the two remaining alternative versions of word order for the initial sentence: the BA construction and the BEI construction. The two named characters introduced in the first sentence were the same gender. The second sentence had two kinds of discourse relationships with the initial sentence: continue and shift. The grammatical subject of the second sentence was realized in the form of a phonologically null (or 'zero') pronoun. A self-paced reading task was used to examine the reading of passages such as the one shown in Table 5.

If grammatical functions determine prominence, the results of this experiment should closely track those in Experiment 3: there should be a significant contrast between the BA and BEI constructions and there should also be a significant continue/shift contrast in each construction. This is because the grammatical functions in the stimuli have not been varied; only their structural and phonological realizations have been manipulated.

\subsection{Method}

\subsubsection{Participants}

Forty-four new students were tested in this study. They were all from the same population as in Experiment 3 (NCCU).

\subsubsection{Stimuli, design, and procedure}

The same set of 32 three-sentence passages in the previous three experiments was employed in this experiment. Appropriate changes were made for the initial sentence of each passage in terms of word order; only the BA and BEI forms were used in the experimental passages. It should be noted, however, that the filler passages included many sentences with canonical structure. In addition, the second sentence in the experimental passages was modified in terms of the form of pronominal expressions used (null pronoun). The experiment was designed and conducted in the same manner as in previous experiments.

\subsection{Results}

Fig. 4 shows the mean reading time for the critical sentence as a function of experimental conditions. After examining the distribution of response times, responses below $450 \mathrm{~ms}$ or above $4800 \mathrm{~ms}$ were considered outliers; excluded observations comprised $4.6 \%$ of the data. The results indicated that when the first sentence used the BA structure, the reading time for the continue condition was as fast as for the shift sentence. However, when the first sentence was the BEI structure, again, the reading time for the continue condition was faster than that for the shift condition. ANOVA showed that the main effect of word order (BEI/BA) was not significant $\left(F_{1}(1,43)=0.20, \quad P=0.655\right.$; $\left.F_{2}(1,31)=0.20, P=0.659\right)$. The main effect of the continue/shift reached statistical significance by participants $\left(F_{1}(1,43)=9.78, P<0.01\right)$ as well as by items $\left(F_{2}(1,31)=7.34, P<0.05\right)$. The interaction between the word order and the discourse relation was significant by participants $\left(F_{1}(1,43)=11.76, P<0.01\right)$, though it fell some- 
Table 5

The sample passage of Experiment $4^{\mathrm{a}}$

\section{Initial Sentence}

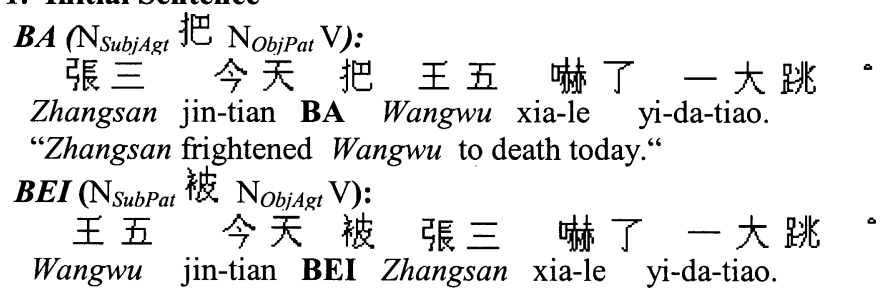

\section{Second Sentence (for BA order)}

\section{Continue}

$\varnothing$ 嚇了人以後哈哈大笑自鳴得意。

$\varnothing$ xia-le-ren yi-hou ha ha da xiao zi-ming-de-yi.

"(He) was very happy after doing so."

Shift

$\varnothing$ 畨場就嚇霉了過去不省人事。

$\varnothing$ dang-chang jiu xia-hun-le gua-qu bu-xing-ren-shi.

" $(\mathrm{He})$ was very frightened and fainted on the spot."

\section{2' Second Sentence (for BEI order)}

Continue,

$\varnothing$ 皆場 就嚇穴了過去不省人事。 $\varnothing$ dang-chang jiu xia-hun-le gua-qu bu-xing-ren-shi.

" $(\mathrm{He})$ was very frightened and fainted on the spot."

\section{Shift'}

$\oslash$ 嚇了人以復哈哈大笑自鳴得意

$\varnothing$ xia-le-ren yi-hou ha ha da xiao zi-ming-de-yi.

" $(\mathrm{He})$ was very happy after doing so."

\section{Passage-final Sentence}

\section{亂嚇人是一件很要不得的行為。}

luao-xia-ren shi yi-jian heo yao-bu-de di xing-wei

"Playing tricks is not supposed to go as far as this."

\footnotetext{
${ }^{a}$ The initial sentences introduced two name named characters of same genders with two alternative versions of word orders (BA/BEI). Both the grammatical subject Zhangsan (訇三) and the grammatical object Wangwu (王开) are conventionally male names. The subject pronouns of the second sentence are in the form of null pronoun.
} 


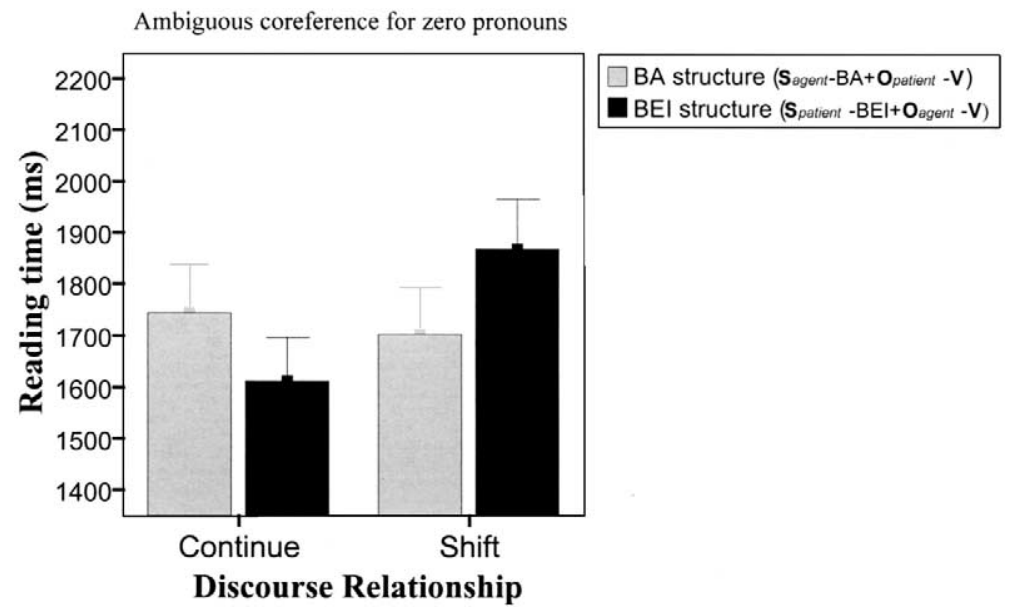

Fig. 4. Mean reading times (ms) of the critical sentences in Experiment 4 as a function of the experimental manipulations. Error bars show the $95 \%$ confidence interval of the mean.

what short of significance by items $\left(F_{2}(1,31)=4.14, P=0.051\right)$. Separate contrasts showed that the continue/shift effect was significant for the BEI structure $\left(t_{1}(43)=3.95, P<0.001 ; t_{2}(31)=2.60, P<0.01\right)$ but not for the BA structure $\left(t_{1}(43)=-0.611, P>0.5 ; t_{2}(31)=-0.401, P>0.5\right)$. The mean accuracies for comprehension questions were: BA-continue (88.2\%), BA-shift (86.5\%), BEI-continue (85.9\%), and BEI-shift (84.1\%). Experimental manipulations had no significant influence on accuracy.

\subsection{Discussion}

The results of this experiment showed that, when the first sentence was the BEI structure, the reading time of the second sentence was faster in the continue condition than in the shift condition. This finding was consistent with what has been found in Experiment 3 . The results of this experiment further showed that, when the first sentence was the BA structure, the reading time of the second sentence in the continue condition was the same as that in the shift condition. This pattern contrasted with Experiment 3. In that earlier experiment, when the first sentence had the BA structure and the subject pronoun of the second sentence was an overt pronoun of ambiguous co-reference, the reading time was faster in the continue condition than in the shift condition. When assessed in the light of our earlier experiments, the results of the current experiment suggest that the direct object in the BA structure had greater prominence than the grammatical object in the Canonical structure; otherwise we would be unable to explain why the Canonical structure shows a significant continue/shift contrast when there is a phonologically unexpressed pronoun in the following sentence (as demonstrated in Yang et al., 1999, 2001), but the direct object in the BA structure fails to do so. In this respect, the direct object in the BA structure patterns with the subject of the Canonical structure when a phonologically unexpressed subject begins the following sentence. Yet, when we compare the results of Experiment 4 
with those of Experiments 1 and 3, we find that the direct object in the BA structure patterns with the object of the Canonical structure when an overt subject starts the following sentence.

Taken as a whole, these results are surprising. They appear to be inconsistent with the claim that grammatical relations determine prominence because we have two direct objects (one in passages where the BA structure is followed by a phonologically null subject, and one in which the BA structure is followed by a phonologically overt subject) that appear to have different degrees of prominence. In other words, the overt ambiguous pronoun in Experiment 3 gave a significant continue/shift effect following the BA construction while the current experiment showed that the phonologically null pronoun did not. Yet the grammatical function account is committed to the claim that prominence is defined at a level that is purposely designed to be insensitive to factors of structural and phonological realization. These results also challenge explanations couched in terms of the hierarchical organization of these constructions if they operate exclusively on structural information and do not distinguish phonologically overt categories from phonologically null categories. Gordon and Hendrick (1997) advocated such a model, and the self-paced reading time experiments on Chinese reported in Yang et al. (1999) offered support for this assertion. It was found that the Canonical structure led to no significant difference in reading time of a succeeding sentence containing an overt as compared to a phonologically null subject. Our results tend to suggest that this method, like the appeal to grammatical functions, is not sufficiently fine tuned to syntactic structure to distinguish prominence in the canonical word order and in the BA structure. ${ }^{10}$ In Section 6, we outline a possible approach that overcomes this limitation.

\section{General discussion}

A series of self-paced reading time experiments investigated how the comprehension of pronominals in Chinese is modulated by their form (overt vs. phonologically null), their discourse relation to the preceding sentence (continue vs. shift), and the word order of the preceding sentence (Canonical, BA or BEI) as illustrated in Table 1. Experiment 1 showed that reading times of sentences containing overt pronouns that had ambiguous reference in terms of gender were slower in the shift condition than in the continue condition, regardless of whether the preceding sentence had a canonical or BEI structure. Experiment 2 revealed that this main effect of continue vs. shift disappeared when the referent of the pronoun was unambiguous on gender grounds, but that following the BEI structure reading times were significantly slower in the shift than the continue condition. Experiment 3 showed that sentences containing overt pronouns whose reference was ambiguous on gender grounds were read more slowly in the shift condition following sentences with

\footnotetext{
${ }^{10}$ It is worth noting that the results we report here are also at odds with the traditional analysis of Chinese linguists (Chao, 1968; Tsao, 1977) who argue for a more pragmatic approach to the use of the BA construction. Our results conflict with this approach because participants do not receive any kind of contextual information before they read the initial sentence of each passage in the reading task. Thus, the increase in the accessibility of the referent introduced by the direct object of the BA structure cannot be attributed to contextual information preceding the reading of that initial sentence.
} 
Canonical, BA and BEI structures, and further that sentences were read more slowly in general following the BEI structure. Experiment 4 demonstrated that the effect of the continue/shift manipulation on reading times of sentences with phonologically null pronouns interacted with whether the preceding sentence had the BEI or BA structure; a significant continue/shift effect was found following the BEI structure but not following the BA structure. These results shed light on the dynamics of how pronominals are resolved in the course of language processing by showing that the ease of determining the referent of a pronominal is strongly influenced by two factors: the lexical features of the candidate antecedent as well as its syntactic prominence.

The matching of lexical features is an important constraint on the choice of a candidate antecedent, but it has more importance as the prominence of that candidate increases. This conclusion is a significant finding because it gives us some insight into how these factors function. Constraints, or negative filters, can interact in several ways. They can operate serially or in parallel, and they can apply conjunctively or disjunctively. It has been suggested that the candidate set of potential antecedents for a pronoun is filtered out prior to the application of other constraints such as lexical matching (cf. Nicol \& Swinney, 1989). This serial hypothesis has been shown to be in conflict with the results of self-paced reading time studies in English reported in Badecker and Straub (2002). Our Chinese findings lead us to a similar conclusion because lexical matching facilitates comprehension but this advantage is diminished when the syntactic prominence of a potential antecedent is low. Our findings also suggest that the constraints involved in pronoun resolution apply in a conjunctive (or additive) fashion rather than in a disjunctive fashion. In the psychological literature disjunctive constraints are characterized as operating in a "winner-take-all" fashion. The linguistic literature has suggested that both kinds of constraints have a role in explaining patterns observable in natural language (cf. Anderson, 1992; Andrews, 1982; Aronoff, 1976; Kiparsky, 1973). Irregular morphological forms, for example, appear to compete with regular forms and block them out (e.g. irregular leaves blocks out the regular *leafs). On the other hand many phonological patterns operate in tandem: the requirement that vowels lengthen before voiced stops and the requirement that intervocalic stops flap can both apply in words such as writer. The lexical matching filter and the syntactic prominence filter do not appear to compete for application in the way irregular and regular morphological patterns do. Instead they interact in tandem, conjunctively. If this conclusion is a general one, and none of the filters relevant to pronoun resolution operate in a disjunctive or "winner-takeall" fashion, we will confront an important design feature of natural language. There is some reason to believe that this feature may be shared by language comprehension processes generally. Li et al. (1993) report the results of an off-line reaction-time study designed to explore how nominals are assigned semantic roles in Chinese. In that work, too, there was significant interaction among a range of morphological and syntactic factors that help identify agents.

The factors that determine syntactic prominence, broadly construed, have also been explored here. Our third experiment showed that Chinese utterances expressing the same semantic content (i.e. utterances with the same truth conditions) do not assign a constant prominence value to their semantic arguments. The results of that experiment indicate that the shift condition with an overt pronoun is read more slowly following the BEI structure 
than following the canonical or BA structure, even though the set of semantic roles is held constant in each structure. Experiment 4 found that the direct object of the BA construction has more prominence for a subsequent, phonologically null subject than it does for a subsequent, overt subject as in Experiment 3. Further, if we complement the results of these experiments with the findings of Yang et al. (1999, 2001), the direct object of the BA construction has more prominence for resolving a phonologically null subject than the direct object of the Canonical structure has. This resulting picture is problematic for the hypothesis that prominence is a direct product of grammatical functions. It is equally problematic for definitions of prominence in terms of phrasal structure. Structural definitions of prominence cannot simply take the depth of a candidate antecedent from the root of a clause as a measure of the candidate's prominence because they must distinguish structures which lack phonologically expressed subjects just when such subjects follow the BA construction.

The problems in defining the syntactic contribution to prominence just noted could potentially be surmounted in several ways drawing on recent developments in different families of syntactic theories. For example, one might attempt to retain the basic notion that prominence is a product of grammatical functions by inflating the set of grammatical functions. One could recognize two kinds of direct objects, privileging one with higher prominence. Something like this alternative is advocated by Bresnan and Moshi (1990) in a study of the syntax of Bantu languages undertaken in a lexical functional theory of syntax. They distinguish a class of "restricted" direct objects from a class of non-restricted direct objects in order to explain how "applicatives" (structures that appear to have two direct objects like the English Jill baked Sandy a cake) interact with a range of other constructions in Bantu. From this perspective the BA construction could draw on this privileged restricted direct object while the canonical word order could make use of the (non-restricted) direct object with lower prominence.

Alternatively, the intuition that the phrasal structure of an utterance determines prominence could potentially be preserved by making the calculation of prominence sensitive not only to the depth of embeddedness of a candidate antecedent, but also to whether it is within a phrase headed by a lexical or functional head. Lexical heads of phrases are "open" categories in the sense that they have many members and they allow coinage of new members. Functional heads of phrases are "closed" categories (such as pronominal articles) that have a small number of members and resist coinage (cf. Grimshaw, 1997). The particle BA, studied here, is a functional category. In principles and parameters theories of syntax, nominals appear within functional phrases only if they have been promoted to that position out of a lexical phrase where they receive their semantic role. One might hypothesize that appearing in a functional phrase is associated with an increase in prominence. From this perspective, a nominal appearing in a functional phrase would then be associated with greater prominence than a nominal appearing in a lexical phrase even when their semantic or grammatical functions are invariant. This claim corresponds to our results: the complement of the functional head BA has more prominence than the complement of the lexical verb in the canonical structure.

As far as we can see, the choice between these two lines of explanation adumbrated above will not help decide between competing theories of the general architecture of linguistic theories. The greater prominence of the object in the BA construction could 
be coded in a lexical function linguistic theory or in a principles and parameters theory. For either the phrasal or grammatical approach to be successful, however, it will need to provide an explanation for why the BA construction shows a significant continue/shift effect only when the following sentence begins with an overt pronoun. No explanation that determines prominence on the grammatical function or the structure position of the direct object of BA alone will accomplish this task. A successful account will need to say something about the relation between the direct object of BA and the phonological presence of the subject of the subsequent utterance. While we do not believe our findings bear directly on the general choice between kinds of linguistic theories, we do believe that they provide important evidence for the phrasal explanation of this inter-clausal, discourse relation.

A descriptively adequate account will explain why the BA construction shows a continue/shift effect only when the following sentence begins with an overt pronoun, but not when the second sentence lacks an overt subject. We are pessimistic about attempts to explain this generalization in exclusively semantic terms. The effect of the BA construction on pronominal resolution stands in marked contrast to its apparent role in the comprehension of semantic roles: $\mathrm{Li}$ et al. (1993) report that BA is a weak cue for the interpretation of semantic roles such as agent and patient. Yet our fourth experiment suggests that BA is an effective cue for local discourse coherence when a subsequent utterance lacks an overt subject pronoun. Further, it is unclear to us how one could frame a natural explanation for this surprising pattern of pronoun resolution making use of grammatical functions exclusively since these functions are designed to be independent of their phonological realization in the phrasal organization of a sentence. We do believe that there is a viable and interesting structural account of the generalization worth further exploration. Consider the example stimuli from Table 1. If the structure of a BA sentence is as in (8), it is possible to analyze the second utterance, which lacks a phonologically overt pronoun, as a simple VP without a subject. Such an assumption converges on the Bresnan (2001) treatment of phonologically null subjects in languages like Chinese that lack rich patterns of verb agreement that we sketched at the outset of this article; there is no second overt subject for $\mathrm{VP}_{2}$ in the phrasal organization of the sentence. However, we continue to assume that prominence is characterized structurally rather than in terms of a hierarchy of grammatical functions, as Bresnan assumes. This allows us to distinguish the pattern of prominence in sequences of utterances where the BA construction is followed by a sentence with a phonologically null subject from a sentence with a phonologically overt subject. In particular, the first stimulus sentence can be parsed in a fashion similar to (8). When the second stimulus sentence is encountered, it can be analyzed as a bare VP that is dynamically conjoined to the VP in (8) as a type of discourse continuation. This conjunction will produce a new structure in (9). It is common to assume that VPs can be semantically predicated of a more prominent (c-commanding) NP. On this assumption, $\mathrm{VP}_{2}$ in a structure such as (9) can now be predicated of either the subject or the object of BA. ${ }^{11}$

\footnotetext{
${ }^{11}$ Recall that A is said to c-command B if and only if every branching category that dominates A also dominates B. As an alternative to the adjunction structure posited in the text, one could try to analyze these structures as conjunction structures. We note in this regard that Chinese lacks an overt morpheme signaling VP conjunction or sentential conjunction.
} 

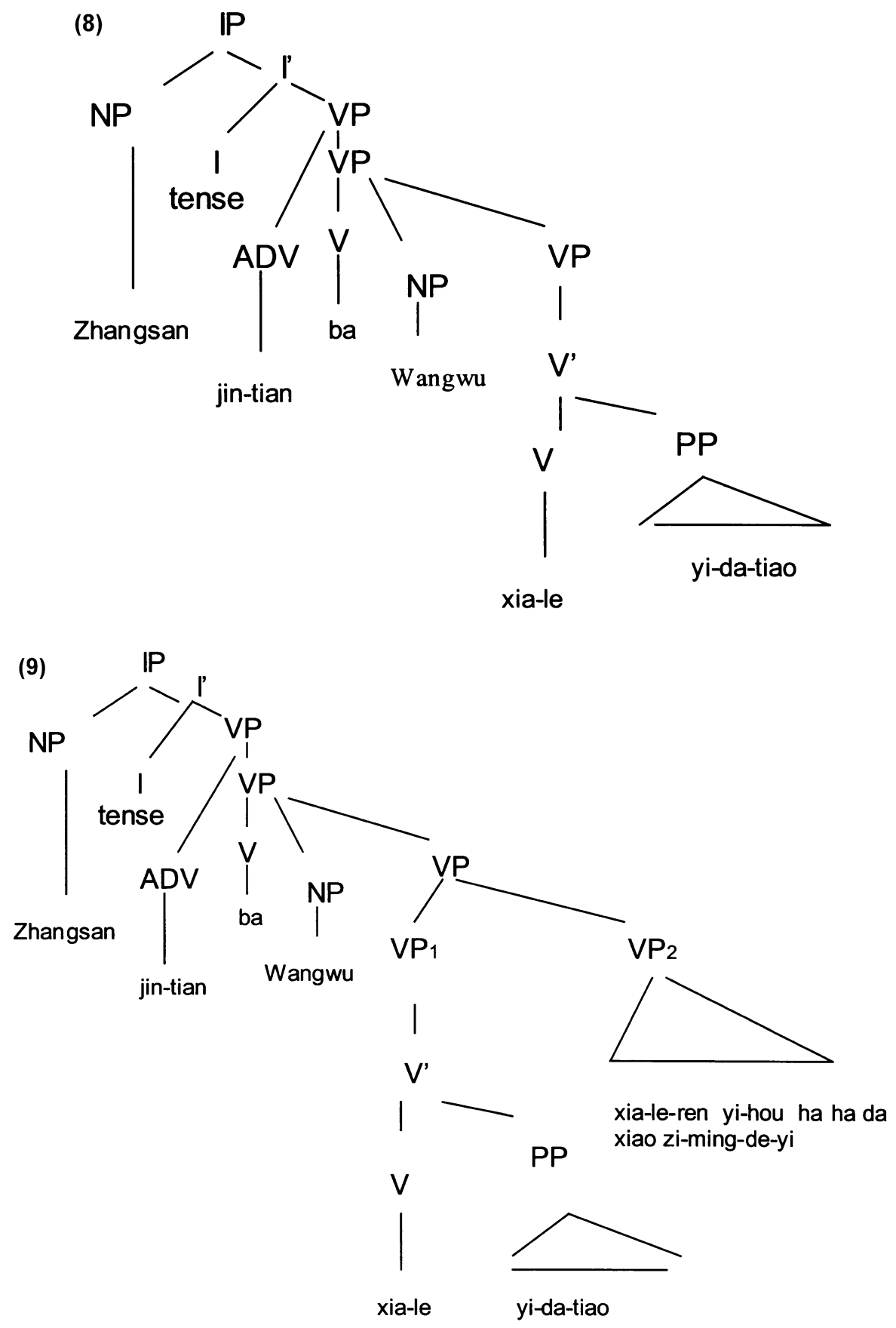
The crucial feature of this hypothesis is that no similar VP conjunction option is available when the second utterance has an overt subject. It is generally assumed that only phrases of the same syntactic and semantic type can be conjoined. If the second utterance is a complete clause with an overt subject (an IP in our parse) it can conjoin only with another IP and not a VP. In that situation the structural conditions for predicating the $\mathrm{VP}_{2}$ of the object of BA are not met because the object of BA fails any longer to be more prominent than (or to c-command) $\mathrm{VP}_{2}{ }^{12} \mathrm{VP}_{2}$ can only be predicated of the overt subject of the second clause because it is the only NP that will c-command it, as can be seen in (10). ${ }^{13}$

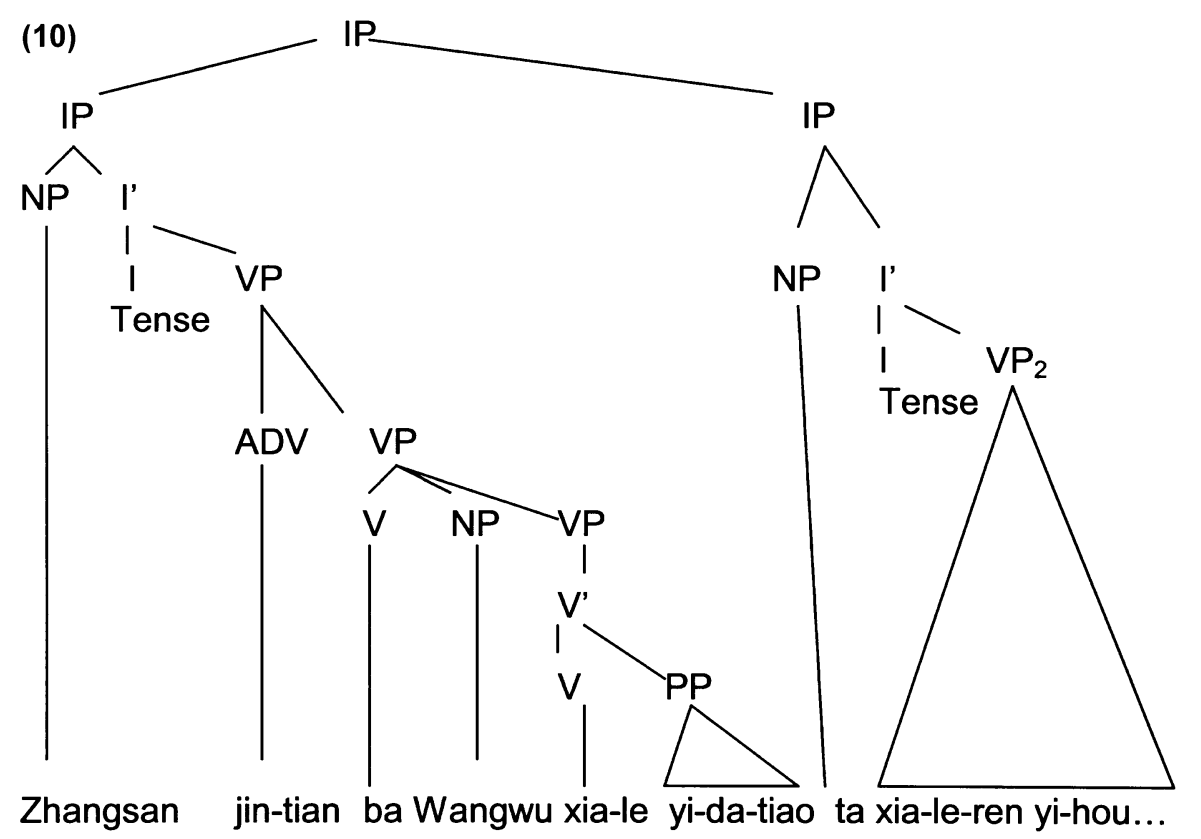

\footnotetext{
${ }^{12}$ When $\mathrm{VP}_{2}$ is predicated of the direct object of BA the structure resembles the so-called "retained object" construction discussed in Huang (1982, p. 42).

Ta ba

wige pingguo

He BA

five apple

chidiao-le

liangge

Of the five apples he ate two.

two

${ }^{13}$ It is worth pointing out that the Canonical structure does not show a similar differential effect when the subsequent sentence has a phonologically null subject. This difference between the Canonical structure and the BA structure follows from the terms of our analysis. It is not possible to conjoin the bare VP of the subsequent sentence to the Canonical structure. To do so would require that the main verb raises to the causative [v e] in (4) out of a conjoined VP headed by the lexical verbs. Yet it is well established that conjuncts are islands for movement (e.g. subjects and modals cannot invert to form a yes/no question when part of a conjunct: *is Jill dancing and Bill has sung). This means that when a Canonical structure is used, only adjunction to IP is available regardless of whether there is a phonologically null subject or not. Again, it is difficult to see how an analysis framed exclusively in terms of grammatical functions could explain in a principled way the different patterns posed by the Canonical structure and the BA structure when the subsequent sentence contains a phonologically unexpressed subject.
} 
In essence we are claiming that, when the BA structure is followed by an utterance with a phonologically overt subject pronoun, a bi-clausal analysis of the discourse is forced. When no overt subject is present, a mono-clausal analysis of the two stimuli sentences is possible, where the two VP predicates are treated as conjoined. This structural account of our Chinese results will be difficult to mimic exclusively in terms of grammatical functions. The problem is that the same pattern of grammatical relations is required by a verb's lexical entry, regardless of whether one maps those grammatical functions onto a structural series of two IPs, or two VPs.

The experiments reported here provide a basis to believe that a modified account of prominence for pronoun resolution that is sensitive to the phrasal organization of successive utterances in a discourse is an integral component of the foundation on which to construct a theory of discourse coherence. Most research in this domain has been conducted on English. We believe that cross-linguistic studies of language comprehension, similar to what we report in this paper, will be increasingly valuable to the further development of such a theory. Our Chinese findings have provided some of the first experimental evidence that variation of structural positions other than the subject position have distinct prominence effects on pronoun resolution. This finding contradicts the widely shared intuition (based on studies of English exclusively) that subjects, but not objects, have by grammatical convention special prominence in discourse (cf. Bresnan, 2001, pp. 97-98; Gordon \& Hendrick, 1998). We are optimistic that further cross-linguistic studies of language comprehension will offer important opportunities to test and sharpen the alternatives we have explored here, as well as the validity of our conclusions about the role of an utterance's phrasal organization in the resolution of phonologically null and overt pronouns.

\section{Acknowledgements}

The research reported here was supported by a Chiang Ching-Kuo Foundation Dissertation Fellowship 2000 to Chin Lung Yang from the Chiang Ching-Kuo Foundation for International Scholarly Exchange and by a grant from the National Science Foundation (BCS-0112231). We would like to thank Dr Nai-Shing Yen of National Cheng-Chi University for advice in experiment designs and helping to recruit participants, and two anonymous reviewers for helpful comments on the paper.

\section{References}

Anderson, S. R. (1992). Amorphous morphology Cambridge: Cambridge University Press.

Andrews, A. (1982). The representation of case in modern Icelandic. In J. Bresnan (Ed.), The mental representation of grammatical relations (pp. 427-503). Cambridge, MA: MIT Press.

Aronoff, M. (1976). Word formation in generative grammar Cambridge, MA: MIT Press.

Badecker, W., \& Straub, K. (2002). The processing role of structural constraints on the interpretation of pronouns and anaphors. Journal of Experimental Psychology: Learning, Memory, and Cognition, 28, 748-769.

Bresnan, J. (1999). Explaining morphosyntactic competition. In M. Baltin \& C. Collins (Eds.), Handbook of contemporary syntactic theory. London: Blackwell.

Bresnan, J. (2001). Lexical-functional syntax. London: Blackwell. 
Bresnan, J., \& Moshi, L. (1990). Object asymmetries in comparative Bantu syntax. Linguistic Inquiry, 21, 147185.

Chao, Y. R. (1968). A grammar of spoken Chinese. Berkeley, CA: University of California Press.

Chomsky, N. (1986). Knowledge of language: its nature, origin and use. New York: Praeger.

Crawley, R. A., Stevenson, R. J., \& Kleinman, D. (1990). The use of heuristic strategies in the interpretation of pronouns. Journal of Psycholinguistic Research, 19, 245-264.

Dowty, D. (1991). Thematic proto roles and argument selection. Language, 67, 547-619.

Ehrlich, K. (1980). Comprehension of pronouns. Quarterly Journal of Experimental Psychology, 32, 247-255.

Fredericksen, J. R. (1981). Understanding anaphora: rules used by readers in assigning pronominal referents. Discourse Processes, 4, 323-347.

Garnham, A., \& Oakhill, J. (1985). On-line resolution of anaphoric pronouns: effects of inference making and verb semantics. British Journal of Psychology, 76, 385-393.

Garnham, A., Traxler, M., Oakhill, J., \& Gernsbacher, M. A. (1996). The locus of implicit causality effects in comprehension. Journal of Memory and Language, 35, 39-68.

Gelman, S., \& Tardif, T. (1998). A cross-linguistic comparison of generic noun phrases in English and Mandarin. Cognition, 66, 215-248.

Gernsbacher, M. A. (1989). Mechanisms that improve referential access. Cognition, 32, 99-156.

Gordon, P. C., \& Chan, D. (1995). Pronouns, passives and discourse coherence. Journal of Memory and Language, 34, 216-231.

Gordon, P. C., Grosz, B. J., \& Gilliom, L. A. (1993). Pronouns, names, and the centering of attention in discourse. Cognitive Science, 17, 311-347.

Gordon, P. C., \& Hendrick, R. (1997). Intuitive knowledge of linguistic co-reference. Cognition, 62, 325-370.

Gordon, P. C., \& Hendrick, R. (1998). The representation and processing of co-reference in discourse. Cognitive Science, 22, 389-424.

Gordon, P. C., \& Scearce, K. A. (1995). Pronominalization and discourse coherence, discourse structure and pronoun interpretation. Memory and Cognition, 23, 313-323.

Grimshaw, J. (1997). Projections, heads, and optimality. Linguistic Inquiry, 28, 373-422.

Grober, E. H., Beardsley, W., \& Caramazza, A. (1978). Parallel function strategy in pronoun assignment. Cognition, 6, 117-133.

Grosz, B. J., Joshi, A. K., \& Weinstein, S. (1995). Centering: a framework for modelling the local coherence of discourse. Computational Linguistics, 21, 203-226.

Hobbs, J. (1979). Coherence and co-reference. Cognitive Science, 3, 67-90.

Huang, C.-T. J. (1982). Logical relations in Chinese and the theory of grammar. Unpublished doctoral dissertation, MIT, Cambridge, MA.

Huang, C. - T. J. (1994). More on Chinese word order and parametric theory. In B. Lust, J. Whitman \& J. Kornfilt (Eds.), Syntactic theory and first language acquisition: crosslinguistic perspectives. Hillsdale, NJ: Lawrence Erlbaum Associates.

Huang, H. S., \& Hanley, R. (1994). Phonological awareness and visual skills in learning to read Chinese and English. Cognition, 54, 73-98.

Jaegli, O., \& Safir, K. (1989). The null subject parameter. Dordrecht: Kluwer.

Johnson-Laird, P., \& Garnham, A. (1980). Descriptions and discourse models. Linguistics and Philosophy, 3, 371-395.

Kayne, R. (1994). The antisymmetry of syntax. Cambridge, MA: MIT Press.

Keenan, E. (1974). The functional principle: generalizing the notion "subject of". In M. LaGaly, R. Fox \& A. Bruck (Eds.), Papers from the tenth regional meeting of the Chicago Linguistic Society (pp. 298-309). Chicago, IL: Chicago Linguistic Society.

Kiparsky, P. (1973). Elsewhere in phonology. In S. R. Anderson \& P. Kiparsky, Festschrift for Morris Halle (pp. 93-106). New York: Holt, Rinehart \& Winston.

Lasnik, H. (1976). Remarks on co-reference. Linguistic Analysis, 2, 1-22.

Li, C. I. (1985). Participant anaphora in Mandarin Chinese. Unpublished PhD dissertation, Linguistic Department, University of Florida, Gainesville, FL.

Li, C. N. (1997). On zero anaphora. In J. Bybee, J. Haiman \& S. A. Thompson (Eds.), Essays on language function and language type dedicated to T. Givon. Philadelphia, PA: John Benjamins. 
Li, C. N., \& Thompson, S. A. (1981). Mandarin Chinese: a functional reference grammar, Berkeley, CA: University of California Press.

Li, C. N., \& Thompson, S. A. (1984). Third person pronouns in zero-anaphora in Chinese discourse. In T. Givon (Ed.), Discourse and syntax (pp. 311-335). New York: Academic Press.

Li, J. -I. J. (1997). The BA construction in mandarin Chinese: a serial verb analysis. In J. R. Black \& V. Motapanyane (Eds.), Clitics, pronouns and movement. Philadelphia, PA: John Benjamins.

Li, P., Bates, E., \& MacWhinney, B. (1993). Processing a language without inflections: a reaction time study of sentence interpretation in Chinese. Journal of Memory and Language, 32, 169-192.

Ma, J.-J. (1935). Mashi Wentong (Ma's grammar). Shanghai: Commercial Press. (Original work published 1898)

MacDonald, M. C., \& MacWhinney, B. (1995). The time course of anaphor resolution: effects of implicit causality and gender. Journal of Memory and Language, 34, 543-566.

MacDonald, M. C., Pearlmutter, N. J., \& Seidenberg, M. S. (1994). The lexical nature of syntactic ambiguity resolution. Psychological Review, 101 (4), 676-703.

Matthews, A., \& Chodorow, M. (1988). Pronoun resolution in two-clause sentences: effects of ambiguity, antecedent location, and depth of embedding. Journal of Memory and Language, 27, 245-260.

McDonald, J. L., \& MacWhinney, B. (1995). The time course of anaphor resolution: effects of implicit causality and gender. Journal of Experimental Psychology: Learning, Memory, and Cognition, 19, 543-566.

McKoon, G., \& Ratcliff, R. (1992). Inference during reading. Psychological Review, 99, 440-466.

Nicol, J., \& Swinney, D. (1989). The role of structure in co-reference assignment during sentence comprehension. Journal of Psycholinguistic Research, 18, 5-19.

Partee, B., \& Bach, E. (1981). Quantification, pronouns and VP anaphora. In J. Groenendijk, T. Janssen \& M. Stokhof (Eds.), Formal methods in the study of language. Amsterdam: Mathematisch Centrum.

Partridge, D. (1991). New guide to artificial intelligence. Norwood, NJ: Ablex.

Reinhart, T. (1983). Anaphora and semantic interpretation. Chicago, IL: Chicago University Press.

Schank, R. (1973). Identification of conceptualizations underlying natural language. In R. Schank \& K. M. Colby (Eds.), Computer models of thought and language (pp. 187-247). San Francisco, CA: Freeman.

Sheldon, A. (1974). The role of parallel function in the acquisition of relative clauses in English. Journal of Verbal Learning \& Verbal Behavior, 13, 272-281.

Shillcock, R. (1982). The on-line resolution of pronominal anaphora. Language and Speech, 25, 385-401.

Smyth, R. (1994). Grammatical determinants of ambiguous pronoun resolution. Journal of Psycholinguistic Research, 23, 197-229.

Strube, M., \& Hahn, U. (1999). Functional centering - grounding referential coherence in information structure. Computational Linguistics, 25, 309-343.

Tsao, F. (1977). A functional study of topic in Chinese: the first step toward discourse analysis. Doctoral dissertation, USC, Los Angeles, CA.

Wang, L. (1955). Zhongguo yufa lilun (theories of Chinese grammar), Shanghai: Commercial Press.

Wentzu Kaiko Chupanshe (1958). Hanyu pinyin fanan. Peiching: Author.

Williams, E. (1994). Thematic structure in syntax. Cambridge, MA: MIT Press.

Yang, C. -L., Gordon, P. C., Hendrick, R., \& Wu, J. -T. (1999). Comprehension of referring expressions in Chinese. Language and Cognitive Processes, 14, 715-743.

Yang, C. -L., Gordon, P. C., Hendrick, R., Wu, J. T., \& Chou, T. L. (2001). The processing of coreference for reduced expressions in discourse integration. Journal of Psycholinguistic Research, 30, 21-35.

Zou, K. (1992). The Chinese BA-construction: a morpho-syntactic analysis. Linguistics, 31, 715-736. 